\title{
Das Políticas de Inclusão à produção de diagnósticos
}

\author{
Alexandrina Monteiro*
}

\begin{abstract}
Resumo
O tema da inclusão tem sido, cada vez mais, alvo de grandes debates e tensões, em especial no interior das escolas. Desse modo, são muitas as perspectivas com que se pode discutir esse tema. Nessa diversidade de possibilidades, optei neste texto por eleger algumas discussões presentes na trama discursiva que emerge na sobreposição dos temas da inclusão, da medicalização e meritocracia. A trama aqui proposta para análise é parte de uma pesquisa ${ }^{1}$ em andamento. Assim, neste texto tenho por objetivo discutir como se entrelaçam alguns dos fios dessa trama e temos por hipótese que algumas das tensões provocadas no jogo de forças dessas tramas são produtoras de novas práticas, dentre elas a que denomino tecnologia do diagnóstico escolar, a qual pode exercer diversas funções no interior da complexa rede de forças que se tecem no espaço escolar.

Palavras-Chave: inclusão; meritocracia; governamentalidade; sociedade contemporânea.
\end{abstract}

\section{From the Politics of Inclusion to diagnostic production}

\begin{abstract}
Inclusion has being increase as a subject in debates and tensions, especially within schools. That is why there are many perspectives to discuss about this thematic. In this diversity of possibilities, I chose in this article to elect some discussions within the discourse emerges in the overlap of the inclusion's theme, the medicalization and the meritocracy. The plot for the analysis proposed here is part of an ongoing research. Thus, in this text, my aim is to discuss the connection between some aspects in this relation as regards the interrelacion of the politics of inclusion and the process of evaluate (external and internal), and also the hypothesis that some of the tensions caused by the "power game" of these plots are producing new practices among them, the one I call the school for technology.

Keywords: Inclusion, meritocracy, governamentality, contemporary society
\end{abstract}

\section{Introdução}

O tema da inclusão tem sido, cada vez mais, alvo de grandes debates e tensões, em especial no interior das escolas. Desse modo, são muitas as perspectivas com que se pode discutir esse tema. Nessa diversidade de possibilidades, optei neste texto por eleger parte dessa tessitura pelo fio das políticas educacionais centradas num processo de avaliação e meritocracia. Ou seja, problematizar as relações de força que se constituem nos fluxos dos discursos meritocráticos - centrados em avaliações: externas e internas - e nos discursos sobre inclusão que sustentam as atuais políticas educacionais no Brasil $^{2}$.

Klein (2009), ao discutir a reprovação no interior da escola, mostra que a avaliação escolar funciona como uma estratégia organizada por um conjunto de táticas didáticas que objetivam operar sobre os sujeitos para reverter a situação de não aprendizagem. Ou seja, numa reprovação "a aprendizagem é vista pela repetição dos conteúdos e das práticas disciplinares, e não pelo sentido da experiência $^{3}$ da aprendizagem para aqueles que aprendem" (p.160).

Por sua vez, a avaliação externa adquiriu centralidade no contexto educacional brasileiro como mecanismo que qualifica as instituições para evidenciar e suprir as carências que mantém o país entre as piores colocações no ranking mundial. Assim, durante a década de $1990^{4}$, no Brasil, consolidaram-se práticas avaliativas de larga escala no âmbito federal e estadual. Tais práticas estão associadas a compromissos assumidos com empréstimos junto ao Banco Mundial, mas que aqui não cabe discutir.

A partir do ano 2000, além da ampliação e diversificação dessas práticas ${ }^{5}$ avaliativas de larga escala, alguns municípios passaram a desenvolver iniciativas próprias de avaliação. Assim, a ampla maquinaria de avaliação do Estado vem por mais de duas décadas produzindo discursos sobre a escolarização centrados em índices, méritos e rankings que, se no início tinham por objetivo evidenciar e suprir as necessidades dos processos de escolarização, hoje apresentam-se como dispositivos de vigilância e controle das práticas docentes e são utilizados em alguns Estados do

\footnotetext{
* Endereço eletrônico: math_ale@uol.com.br
} 
Brasil como um dos principais critérios para a definição de investimentos nas instituições escolares.

Apesar de as avaliações externas nos possibilitarem uma longa e profícua discussão, esse não é o objetivo deste texto; assim, retorno à ideia da tessitura inicial na qual me propus a buscar alguns dos nós que entrelaçam os fios das práticas de avaliação e os processos de inclusão.

Paralelamente a essa análise do rendimento dos escolares (crianças, jovens ou adultos) realizada pelas avaliações externas, as escolas brasileiras vivem sob o jugo dos discursos da educação $n a$ e para a diferença. A esse respeito GALLO (2009, p.7) questiona o sentido da inclusão e pergunta: "Mas compreendemos de fato a diferença? Vivemos a diferença, ou ela está apenas em nossos discursos?". É no interior dessa rede discursiva que diversos sentidos são atribuídos à diferença e a educação inclusiva. Interpretações de sentido que agregam práticas, agem, e afetam os modos de vida, em especial, os modos como se organizam os processos educativos. Afinal,

Toda interpretação é determinação do sentido de um fenômeno. $O$ sentido consiste precisamente numa relação de forças, segunda a qual algumas agem e outras reagem num conjunto complexo $e$ hierarquizado. Qualquer que seja a complexidade de um fenômeno, distinguimos bem forças ativas, primárias, de conquista e subjugação, e forças reativas, secundárias, de adaptação e de relação (Deleuze, 1994, p.21).

Nesse jogo de forças as práticas de inclusão e as ideias de meritocracia vinculadas às práticas de avaliação vão tecendo contornos de uma certa tessitura do um espaço escolar centrado no ímpeto de universalização e equidade da educação. A universalização e equidade são os termos chave dos discursos que proclamam que TODOS devem participar dos processos de escolarização, tal como acordado na Declaração Mundial sobre Educação para Todos de 1990, que ocorreu em Jomtien na Tailândia, seguido da declaração de Salamanca, na Espanha, ocorrida em 1994, que tinha como foco específico políticas e práticas na área das necessidades educativas especiais.

Enfim, todas essas declarações são fundamentais na consolidação e legitimação de propostas de práticas inclusivas no contexto escolar.
E, no interior do contexto escolar, essas forças se entrelaçam com os processos de avaliação, que, como dissemos anteriormente, vigiam e falam sobre a qualidades das escolas e do ensino, o que, por sua vez, vêm ao encontro de propostas que sustentam modos de vida contemporâneo, centrados num modelo econômico neoliberal, conforme discutiremos mais à frente.

Para tanto, o texto divide-se em quatro partes. Na primeira, abordo a consolidação de práticas de meritocracia associadas ao modelo neoliberal; numa segunda, discuto os efeitos da inclusão nas práticas de avaliação externa e interna da instituição escolar; na terceira, abordo a produção de tecnologias que produzem diagnósticos escolares, bem como o sujeito diagnosticado e, por fim, apresento alguns ruídos que ecoam dessas discussões.

\section{Meritocracia como estratégia educacional neoliberal}

No modo de vida neoliberal, em que cada vez mais o Estado e o Mercado estão articulados em promover na população valores baseados no autocontrole, no fortalecimento das leis de mercado, entre outros, a escola torna-se um lugar privilegiado para a intersecção de forças advindas da inclusão (todos devem participar do jogo) e da meritocracia (a participação implica ocupar um lugar demarcado), consolidando modos de subjetivação que atendam às demandas de uma sociedade centrada em tais valores.

O discurso da inclusão vem, assim, atender a um movimento reivindicatório legítimo e construído por longas décadas, mas que se efetiva de forma lenta e traumática, já que a escola parece não estar estruturada para acolher essa nova demanda. Isso porque as diferenças tão anunciadas e defendidas nos discursos da escola inclusiva se apagam ao ter que se adaptarem ao modelo escolar meritocrático estabelecido. Pois, na prática, o processo de inclusão nas escolas têm significado acomodar e adaptar as diferenças frente aos currículos, aos tempos e aos espaços escolares, bem como aos processos avaliativos que os sustentam.

Por sua vez, esses processos avaliativos, em tempos de valorização do mercado e de forte dominação do discurso empresarial, têm como objetivo a formação do indivíduo capaz de ser um empresário de si mesmo, ou seja, o papel da escola deve ser o de estimular seus alunos a terem iniciativas próprias, autogestão, e responsabilidade. 
$\mathrm{O}$ indivíduo deve produzir-se reconhecendo-se dentro do jogo competitivo que a economia de livre mercado exige. Deve produzir-se no que VeigaNeto (1999, p.9) denominou de Homo manipulabilis que para esse autor significa a dizer que o indivíduo não carrega em si um a priori econômico, mas, ao contrário, é um indivíduo flexível, "é alguém que pode e deve ser levado a se comportar dessa ou daquela maneira no mundo da economia - que na lógica neoliberal, equivale a dizer simplesmente: no mundo".

Castro-Gómez (2010) reforça essa forma de existência proposta pelo modelo neoliberal, ao argumentar que nessa perspectiva os sujeitos devem ser capazes de racionalmente escolher os meios adequados para "realizar-se a si mesmos" e deverão converter-se em "empresário de si mesmos". Para garantir essa conversão de empresários de si mesmos e para aprender a jogar com suas próprias "competências", a passagem desses indivíduos pela escola é fundamental, pois, para participar dessa empreitada é necessário ser educado para entrar no jogo; para permanecer no jogo (permanecer incluído); e para desejar permanecer no jogo. (Lopes, 2009, p.155).

Assim, o grande desafio aos que participam dos processos de escolarização é conciliar os anseios e desejos de uma escola pensada com base em um modelo fabril, centrado numa sociedade disciplinar para um modelo empresarial, centrado numa sociedade de controle, neste caso num modelo escolar que é fortemente atravessado por avaliações externas além das já consolidadas pelas práticas escolares e que povoam o cenário da aprendizagem escolar desde sua mais remota forma de organização. Mas, na contemporaneidade, acrescenta-se a esses desafios da escola o acolhimento dos mais diferentes casos de inclusão. Nesse sentido a inclusão torna-se mais uma engrenagem da maquinaria escolar, cujo objetivo visa à normalização dos sujeitos, garantindo a formação de uma população civilizada, na qual os sujeitos governem a si e aos outros dentro das normas estabelecidas.

Mas, ao proporcionar essa ampliação, como garantir-se nos rankings externos, como atender a crescente demanda de excelência quando as salas de aula estão cada vez mais povoadas de pessoas que têm seu potencial de aprendiz para temas que não são contemplados e muitas vezes nem legitimados por esses processos avaliativos?

\section{Efeitos da inclusão frente às práticas avaliativas}

Em 1948, três anos após o término da Segunda Guerra Mundial, foi criada a Declaração Universal dos Direitos dos Homens, e esta destacava o direito a educação de todos os indivíduos. Com base nisso, muitas discussões e documentos foram produzidos para garantir esse direito; entretanto somente no ano de 1990 é que a questão da inclusão ganhou espaço privilegiado na pauta da reunião realizada pela UNESCO. Essa reunião, denominada Conferência Mundial na Tailândia, teve por objetivo discutir como se encontrava a educação mundial, e principalmente assegurar o direito ao acesso a escola, independente das diferenças individuais. Ao fim dessa conferência, os países se comprometeram a retornar após quatro anos para socializarem as medidas tomadas e mudanças ocorridas.

Assim, no ano de 1994, noventa e dois países se reuniram na Espanha durante quatro dias, na cidade de Salamanca e realizaram um balanço, no qual discutiram quais medidas cada país havia realizado em prol da educação. Ao término dessa discussão, os governos ali reunidos reafirmaram o compromisso com a garantia da educação para todos e reconheceram a necessidade e a urgência de garantir a educação de crianças e jovens portadores de Necessidades Especiais, e finalizaram a reunião com um documento assinado por todos os participantes: Declaração de Salamanca - o qual se comprometiam em colocar em prática. Mas, o que dizia esse documento?

O documento buscava mudar o olhar da educação para portadores de necessidades especiais, e se baseava em princípios que visavam à preservação da dignidade humana dessas pessoas, garantindo a busca de suas identidades e o exercício da cidadania. Aqui no Brasil foram precisos sete anos para que fosse criado um documento legal para garantir os direitos às pessoas com necessidades especiais, dentre eles o direito a participar das atividades educacionais das instituições escolares tradicionais. Um dos principais objetivos dessas medidas era minimizar o processo de segregação das pessoas que tinham algum tipo de necessidade especial e que por essa razão estudavam - quando estudavam - em escolas ditas especiais.

Analisando alguns documentos referentes a essa temática, tais como o PARECER 17/2001 ${ }^{6}$ Diretrizes nacionais para a Educação Especial na educação Básica e a RESOLUÇÂO CNE/CEB N ${ }^{\circ}$ $02 / 2001^{7}$, podemos notar que existem muitos pontos que, em forma de lei, têm por finalidade assegurar o acesso, permanência e condições mínimas para que 
as pessoas com necessidades especiais possam participar das atividades educacionais escolarizadas.

Esses documentos legitimam, no Brasil, a maior parte da Declaração de Salamanca e garantem que as crianças sejam incluídas à rede regular de ensino, havendo exceção apenas quando os alunos possuem síndromes severas, com necessidades consideradas não cabíveis para uma sala de aula; e, neste caso, devem frequentar uma escola especial. Eles também destacam a importância da formação de professores para trabalhar com esses alunos, e determinam que o Estado (federal, municipal ou estadual) disponha de um departamento que se encarregue de responder pela parte de inclusão nas escolas, prestando apoio especializado às mesmas.

Os documentos afirmam, ainda, que o currículo deve ser adaptado para essa inclusão, assim como o prédio escolar, garantindo o pleno acesso aos alunos nas suas diversas necessidades. E, sobre a avaliação, discorrem que a mesma deve ser realizada com base nos avanços desses alunos considerando-se as necessidades especiais que possuem, e não pelas expectativas do ano/série modelo que se aplica à crianças consideradas "normais".

Acorsi (2009), ao problematizar o discurso das estatísticas relativas a inclusão, mostra que os números parecem impedir qualquer tipo de questionamento: "dados do Ministério da Educação, apontam que entre 1998 e 2006 o crescimento de matrículas de crianças com necessidades especiais foi de 604\%" (p.176). Entretanto a autora aponta também que há outras formas possíveis de se falar sobre inclusão, como a expressão que usa como título de seu artigo: tenho 15 alunos e 5 inclusões. Essa afirmação, por sua vez, aponta para o cotidiano escolar, o qual é demarcado e organizado pela distribuição dos "casos" de inclusão, e mostra a necessidade de se organizar, esquadrinhar, disciplinar a inclusão dentro das normas escolares. Assim, seria possível pensar na inclusão como uma política de respeito às diferenças dentro do atual modelo escolar, dentro de um processo cada vez mais meritocratizado?

Foucault, em curso ministrado no Collège de France em 1975 denominado Os anormais, nos propõe pensar essa relação com o outro, com o diferente, destacando o fato de que a inclusão não é algo bom em si mesmo e nem pode ser entendia como a outra face da moeda da exclusão. Ou seja, ele nos leva a desconstruir o binarismo da lógica platônica: ou se inclui ou se exclui. $O$ que nos permite pensar em processo de inclusão excludente
(Veiga-Neto. 2001).

A tênue relação/tensão entre inclusão e exclusão tem sido um tema amplamente debatido por muitos pesquisadores. Destaco as contribuições do grupo de pesquisa atualmente liderado pela Professora Maura Corsini Lopes. Os estudos desse grupo examinam como as políticas de inclusão podem produzir exclusão, especialmente num modelo social demarcado por numa economia de mercado, que requer dos indivíduos uma forte capacidade de flexibilização e adequação às necessidades, que são fortemente controladas. Diante disso, eles criaram a expressão in/exclusão para atender à provisoriedade determinada pelas relações marcadas por um Estado neoliberal. Ou seja, ao problematizar o caráter natural atribuído ao termo inclusão, Veiga-Neto e Lopes (2011) entendem que:

As políticas que promovem, bem como os usos da palavra inclusão em circulação, afinam-se tanto com a lógica do binário modernos inclusão $x$ exclusão quanto com a lógica contemporânea em que a inclusão funde-se com a exclusão. (p. 125)

E nessa fusão in/exclusão algumas táticas passam a povoar o ambiente escolar. Por exemplo, a distribuição dos alunos que possuem algum tipo de necessidade especial em diferentes salas do mesmo ano/série, atividades paralelas que atendam às especificidades das diversas "síndromes" ou "transtornos", avaliações diferenciadas, já que as atividades realizadas são diferentes. Mas o que me interessa aqui pontuar é o fato de que alunos com algum tipo de transtorno ou síndrome relacionada ou que configure algum tipo de dificuldade no processo de aprendizagem não participam das avaliações externas.

Essa não participação estaria relacionada ao fato de essas provas serem organizadas com base nas expectativas de aprendizagem definidas a priori como um mínimo a ser alcançado pelos alunos no nível de escolaridade avaliado. E, como os alunos de inclusão, a priori, já são reconhecidamente "demarcados" como diferentes, eles não devem atender às mesmas expectativas dos demais; portanto, não faz sentido considerá-los nas estatísticas que classificam o nível das escolas e dos alunos tanto em relação à média nacional quanto internacional. Diante dessa realidade, como não considerar as exclusões promovidas pelas políticas inclusivas? Ou como não pensar nas políticas de 
inclusão como um movimento afinado tanto com $a$ lógica do binário modernos inclusão $x$ exclusão quanto com a lógica contemporânea em que a inclusão funde-se com a exclusão?

\section{A produção de aprendizes}

Como venho afirmando, há em nossa sociedade a necessidade de se estabelecer um padrão de normalidade. Contudo me pergunto: o que é ser normal? Qual é a relação entre a normalidade e a anormalidade? Pode um medicamento me tornar normal? Diante disso, podese considerar que a ideia de anormalidade estabelece um vínculo direto com processos preconceituosos presentes em nosso meio social, que se derivam de questões históricas, políticas e principalmente culturais, e que refletem nos processos de subjetivação exercidos pelas diversas instituições (família, escola, igreja...) a que somos submetidos no mundo contemporâneo.

De um modo geral, os sujeitos considerados "anormais" passam a existir em contraposição com aqueles consideradas dentro da "normalidade", ou talvez os que se consideram normais dependem da definição de anormalidade para poder garantir sua existência. De qualquer modo, o processo de estranhamento parte de um modelo de humanidade considerada normal, adequada e até desejada no interior de uma determinada sociedade, a partir do qual os "outros" que não se adequam a esse modelo são classificados como os "anormais".

Nesse sentido, problematizar os discursos em torno das questões de inclusão torna-se fundamental, pois eles tensionam ainda mais as diferenças e os processos de exclusão, especialmente no contexto escolar. Um dos pontos que fortalece essa tensão é que, no modelo neoliberal que nos atravessa, o qual demarca novas fronteiras que se organizam pelas leis do mercado e pelo PIB dos países priorizando, assim, metas de formação de sujeitos cada vez mais empreendedor e consumidor.

É diante desse modelo de governamentalidade neoliberal que atravessa diversas instituições da sociedade contemporânea, em especial a escolar, que emergem alguns dos dilemas dos professores frente aos processos de avaliação de seus alunos. Afinal, quais seriam as características dos alunos considerados "normais", o que se poderia esperar daqueles considerados "inclusão" quando tenho $x$ alunos e y inclusões? Nas observações de campo da pesquisa que venho realizando, é comum a perceber a tensão dos professores em relação aos processos de avaliação. Essa tensão se faz presente na sala de aula, em reuniões pedagógicas ou até em conversas informais com colegas na hora do lanche. Há sempre uma grande dúvida sobre o que fazer e como encaminhar o aluno considerado como "inclusão". E, nessa condição babélica da escola, as avaliações passam a indicar muito mais do que o quanto a criança está aquém ou além do esperado.

Ao perguntar a uma professora sobre como a equipe pensa a avaliação considerando-se os casos de inclusão ela me respondeu:

(...) Ah! É normal. Quer dizer até hoje não conheci nenhum tipo de avaliação diferente que seja específica para um certo tipo de necessidade especial. A gente cria atividades, faz coisas simples e coloca no prontuário que é aluno de inclusão porque neste caso sabemos que aquele aluno não pode ter notas vermelhas. Assim ele tem nota azul sem atingir os objetivos do anoque são pensados para os alunos normais, mas a gente considera que ele cresceu, porque a gente só pode reprovar se os pais consentirem, assim eles seguem seu rumo (Prof. P.).

Assim, as crianças seguem seu rumo. Espera-se que nessa caminhada se explorem suas potencialidades. Mas como fazer isso? E aqui convido outro professor que, diante dessa discussão, fez o seguinte comentário:

tenho como meta garantir o conteúdo do currículo para o aluno normal porque depois tem Saresp e já viu! E, os outros eu trabalhado dentro das minhas possibilidades. As vezes levo uma atividade a parte (...). Em geral eles demoram várias aulas numa mesma atividade. Mas é só o que consigo fazer (Prof. L).

Foucault (2006) explica que é dito normal o indivíduo que é capaz de moldar-se ao modelo geral previamente tido como norma; sendo assim, o anormal é aquele que não se enquadra nesse modelo. Busca-se então através da "normalização" que se faça "interagir essas diferentes atribuições de normalidade e procurar que as mais desfavoráveis se assemelhem às mais favoráveis". (p.83) E é essa a busca do professor que dentro de suas 
possibilidade adequa as atividades à possibilidades dos alunos. Mas estar na escola significa independente do caso - realizar atividades escritas.

É desse modo que a tênue linha entre normal e anormal produz o que denomino tecnologia do diagnóstico escolar, ou seja, o conjunto de técnicas, de mecanismos disciplinares que compõem os campos de forças que produzem o sujeito "diagnosticado". Os processos de comparação entre normais e anormais possibilitam aos professores identificar - em especial crianças os que se assemelham entre si. Esse processo de similaridade, especialmente nas dificuldades que os alunos apresentam, servem de pistas para a identificação e classificação dos alunos como (possíveis) casos de inclusão.

$\mathrm{Ou}$ seja, alunos com fortes características/sintomas de algum tipo de transtorno mas que não possuem laudo, podem ser considerados de inclusão diante das dificuldades que apresentam no contexto escolar. Neste caso a primeira atitude da equipe pedagógica, em geral, é solicitar aos pais que a criança passe por uma avaliação médica, que pode ou não reafirmar as hipóteses de inclusão. Entretanto o que tenho observado ao longo da pesquisa é que em muitos casos a família não busca essa avaliação, em alguns casos por não possuir recursos para realizá-la. O fato é que, diante da falta de um laudo médico, mantém-se o laudo do diagnóstico escolar, ou seja, a criança é identificada e tratada como um aluno que faz parte do grupo de inclusão - já que as práticas são distintas - e, desse modo, se produz o "sujeito diagnosticado". Mas em que consiste esse sujeito diagnosticado?

\section{Desafios frente à (não) aprendizagem}

Segundo Gallo (2013), a escola moderna é a instituição que se propõe a realizar o projeto da Modernidade, ou seja, garantir a autonomia do homem, sua emancipação pelo esclarecimento, como propôs Kant: esclarecimento é a saída do homem da condição de menoridade auto-imposta. Nessa perspectiva, o processo educativo é de fundamental importância para a formação do homem mais humanizado, autônomo, capaz de emancipar-se, de libertar-se. Para a realização desse projeto, em que o homem é capaz de pensar por conta própria, mas pautando-se na razão, e portanto nas dimensões ético-morais, ele precisa ser escolarizado, precisa ser ensinado e a disciplina passa a ser um fator fundamental. Kant afirma que:
A disciplina é o que impede o homem de desviar-se do seu destino, de desviar-se da humanidade, através das suas inclinações animais. Ela deve, por exemplo, contê-lo, de modo que não se lance ao perigo como um animal feroz, ou como um estúpido. Mas, a disciplina é puramente negativa, porque é o tratamento através do qual se tira do homem sua selvageria; a instrução, pelo contrário, é a parte positiva da educação (Kant, 1996. Apud Gallo, 2013, p.2).

Gallo (2013) afirma, ainda, que, para Kant, a disciplina tem um aspecto positivo e negativo. Ela apresenta-se como negativa porque nega nossa selvageria; entretanto, quando se torna instrução, ela passa a realizar sua parte positiva do processo educativo. Tal processo consiste em quatro etapas: disciplinarização, a instrução (que o coloca no mundo da cultura), a prudência (o fazer que permite a ele reconhecer seu lugar) e a moralização (que lhe permite escolher bons fins).

É nesse sentido que a instituição escolar se serve da disciplinarização, ou seja, a instituição escolar se organiza como uma grande maquinaria cujas engrenagens se prestam a produzir o indivíduo emancipado, valendo-se especialmente de dispositivos disciplinares, que passam a afetar o corpo e a instrução, quando o próprio saber passa a ser também disciplinarizado.

A realização desse projeto institucional é analisado por Foucault especialmente em se livro Vigiar e Punir ${ }^{8}$. Nesse livro, Foucault analisa os diversos dispositivos disciplinares - que formam o que Goffman (2003) denomina instituições totais ou seja, instituições que visam o confinamento vigiado. Essas instituições se ocupam de grupos diferentes, mas dentro de uma mesma lógica - a lógica panóptica. São elas: os conventos, as prisões, as escolas e os hospitais. Essa lógica se caracteriza pela arquitetura: pátios cercados de celas-salasquartos, que permitem aos sujeitos serem vigiados sem o saber. O tempo é dividido em intervalos regulares, com horários para comer, tomar sol, entre outras.

Segundo Foucault, a disciplina associada a esse processo de reclusão é um tipo de tecnologia que produz determinado tipo de sujeito. Um sujeito disciplinado, dócil, não emancipado, autônomo como propunha Kant. Gallo (2013), apoiando-se em Rancière, argumenta que o projeto da modernidade pode ser visto, por um lado, como fracassado, pois 
não foi capaz de produzir o indivíduo emancipado; mas, por outro, podemos testemunhar seu sucesso: a construção de uma sociedade pedagogizada por um emaranhado de relações de poder cujo preço da emancipação é o embrutecimento.

A sociedade moderna como uma sociedade pedagogizada, [é] centrada na lógica do ensino como explicação, que torna o aprendiz sempre dependente de um mestre. Ora, se a educação é planejada como um processo emancipados, que leva o indivíduo da menoridade à maioridade, como pode ser ela uma camisa de força que faz com que todos e cada um sejam sempre dependentes de um mestre que explica? Rancière denomina esse processo como embrutecimento, o exato oposto da emancipação (Iden, p.3).

Nesse processo de embrutecimento, a ordem, a classificação o nível de dependência tornam-se pilares de sustentação dessa instituição. A meritocracia passa a ser um dispositivo de justificação do fracasso do projeto de emancipação. A contínua dependência e embrutecimento passam a ser responsabilidade do sujeito que não possui as qualidades intelectuais ou culturais necessárias para sua suposta libertação. Assim, é necessário classificar, controlar, medir para analisar e buscar recursos que possam superar os problemas que impedem a realização desse projeto.

É nesse sentido que outros dispositivos passam a emergir. Se por um tempo a escola excluía os incapazes, as políticas de inclusão não só criou mecanismos para impedir que crianças fiquem fora da escola, como ampliou a participação daqueles que se quer poderiam entrar por serem portadores de diversos tipos de transtornos.

Dentro dessa nova configuração, a escola tenta se redimensionar dentro do mesmo, ou seja, dentro do próprio espaço já sedimentado, o que a impede de mudar de buscar outras alternativas. Assim, esse redimensionamento passa a ocorrer nos discursos que incluem, excluem ou classificam os sujeitos escolares: as avaliações - que passam a ter um caráter cada vez mais diagnóstico, terapêutico. Ou seja, o discurso produzido pelos processos de avaliação escolar estão cada vez mais atravessados por termos advindos do campo da saúde. São as avaliações diagnosticas que objetivam diagnosticar os sujeitos, classificar, subjetivar.

Assim, do projeto que se propunha a formar o sujeito emancipado chega-se ao sujeito embrutecido e atravessado pelo sujeito diagnosticado: sujeito cuja classificação considera cada vez mais os possíveis transtornos neurológicos, psicológicos que o impedem de tornar-se o sujeito emancipado pelo esclarecimento como pretende(ia) o projeto da modernidade.

Assim, na prática, as políticas de inclusão têm possibilitado a produção de novos dispositivos, novas táticas relacionadas aos processos de avaliação e portanto novas formas de subjetivação, as quais muitas vezes tendem - do meu ponto de vista - produzir diagnósticos (transtornos aprendizagem). Pois, desde o momento em que as escolas recebem alunos considerados de "inclusão", elas utilizam-se de procedimentos e práticas de comparação e classificação, as quais criam os elementos para a produção do diagnóstico escolar bem como do sujeito escolar diagnosticado. Essa prática pode, por sua vez, ser reforçada, negada ou problematizada por uma equipe medica $\mathrm{e}$ psicológica. O fato é que hoje nas escolas, em especial nas séries mais avançadas já percebemos os efeitos dessa tecnologia sobre os sujeitos diagnosticados. Tais sujeitos, ao iniciar séries mais avançadas, são alvos dos mais diversos tipos de estranhamentos/questionamentos, como: o questionamento sobre como esses alunos chegaram a séries tão avançadas; ou ainda o que fazer com eles, já que são analfabetos, entre outros. Assim como, na falta de um reforço ou de uma negação, prevalece o diagnóstico escolar.

\section{Alguns ruídos que ecoam}

Como se já não fosse suficiente pensar em todas as tramas que envolvem a proposta de inclusão, cada vez mais as comuns necessidades educacionais deixaram de ser questões de aprendizagem e passaram a ser tratadas como problemas patológicos. Assim, novos desafios se abrem quando os casos de transtornos de aprendizagem passam a povoar as salas de aula. Neste caso temos os casos de alunos que são: medicalizados; diagnosticados por equipes médicas, mas não utilizam medicamentos porque não é necessário, ou por opção da família ou ainda por falta de estrutura, em geral, financeira. E ainda existem os casos daqueles que possuem o que denominei de diagnóstico escolar.

Ora, esses diagnósticos - com laudos médicos ou não - em sua maior parte são incitados pela própria escola. A instituição escolar, visando a 
atender à lógica da sociedade contemporânea, que tem como responsabilidade alcançar certa metas estabelecidas pelo Estado, procura garantir a aprendizagem de um conjunto de saberes por ano/série, que deveriam possibilitar aos alunos considerados "normais" atingir índices determinados previamente. Nesse sentido, os casos de alunos desatentos, com baixo rendimento, hiperativos enfim, alunos que apresentem algum "sintoma" que possa enquadrá-los como inclusão é de fundamental importância, pois, neste caso, ele deve ser devidamente tratado com o uso de medicamento, quando for o caso, e com atividades escolares diferenciadas, além de não participarem das avaliações externas que produzem os índices e os rankings.

Assim, para atender às demandas e necessidades da sociedade contemporânea que, de um lado, vende a ideia da satisfação e realização dos sonhos e dos desejos e, de outro, atribui ao indivíduo a total responsabilidade por suas conquistas e fracassos, essa sociedade passa a se consolidar como a sociedade do consumo das pílulas e das vitaminas. É considerável o crescimento da indústria das vitaminas, medicamentos fitoterápicos, homeopáticos e alopáticos no mundo inteiro. A indústria farmacêutica atualmente é a segunda em faturamento no mundo.

Gostaria ressaltar que a pesquisa que desenvolvo - e da qual emerge este texto - não tem, em nenhuma instância, por objetivo julgar os tratamentos médicos, ou questionar quaisquer laudos emitidos, práticas escolares ou a posição das famílias frente aos diferentes processos de avaliação. O que gostaríamos de ressaltar é a complexidade das relações que se estabelecem em torno da temática da inclusão quando relacionada à ideia de meritocracia. Mesmo que pontual, o que se espera ao mexer nessas linhas, é causar ruídos talvez que dissonantes; mas ruídos que ecoem, que incomodem, que nos mantenham alertas e abertos para buscar diferentes possibilidades de encaminhamento e de formas de abordar a nãoaprendizagem no contexto escolar.

Desse modo, ao pensar as políticas de inclusão vinculadas aos processos de avaliação externa, como também às avaliações escolares a que são submetidos os alunos, percebemos uma intricada teia de relações que, ao se conectarem, produzem pontos de tensão como, por exemplo, quando associamos a avaliação externa aos rankings e as definições de financiamento. Os índices produzidos por essas avaliações consideram o rendimento dos alunos com base em uma única avaliação, que é aplicada a todos os alunos de uma determinada série de um mesmo Estado ou do Brasil. Todos realizam a mesma prova. Afinal, em tese, somos todos iguais e temos os mesmos direitos.

É diante da homogeneização das massas que professores e gestores traçam suas metas, visando ao bom rendimento de seus alunos; afinal, o resultado desses exames podem comprometer os planos e as verbas escolares e, em alguns casos como no Estado de São Paulo -, comprometem até o salário dos professores. Mas, ao focar o rendimento dos alunos, os casos de inclusão tornam-se pontos de tensão. Destaco dois deles, um relacionado ao tempo, pois exigem que o professor trabalhe com atividades diferenciadas do restante da sala. E outro, relacionado ao rendimento escolar daqueles que apresentam muitas dificuldades de aprendizagem (característica de um aluno de inclusão) e que, mesmo não possuindo laudo, passam a ser tratados como um aluno de inclusão. Porém, neste caso cabe ao professor assumir os riscos decorrentes desse diagnóstico escolar. Tanto em relação à aprovação ou reprovação quanto à participação desses alunos nas avaliações externas.

De qualquer forma, os diagnósticos produzidos pela escola ou pelas equipes médicas provocam movimentações, processos de subjetivações e formas de controles, assim como podem produzir táticas de impedimento desses alunos, pois podem provocar tanto a reprovação como a não-participação em avaliações externas -, quando acompanhadas de um laudo médico ou psicológico que legitime o diagnóstico escolar. $\mathrm{O}$ desafio que se impõe é o de criar possibilidades outras, é o de compreender a complexidade e, assim, desconfiar de discursos tomados como naturais e verdadeiros, pois pensar a experiência pedagógica com desconfiança permite que outros espaços se potencializem; logo, é um convite a pensar de outro modo os modos pensados, os modos já postos.

\section{Notas}

1 pesquisa de pós-doutorado intitulada: Processos de medicalização escolar e subjetivação: um estudo a partir de deslocamentos em Deleuze e Foucault - desenvolvida na Faculdade de Educação da Unicamp sob supervisão do professor Silvio Gallo. 
2 As avaliações externas que se iniciaram no âmbito nacional e hoje já possuem diferentes versões (ex. Provinha Brasil, ANA - avaliação nacional de alfabetização; ENEM) e se configuram em contextos: internacional (PISA), estadual (ex. SARESP) e municipal.

3 Experiência no sentido de Larrosa (2002), como um encontro ou uma relação com algo que se experimenta, que se prova. Segundo Klein (2009) O sujeito dessa experiência seria aquele capaz de se expor, atravessando um espaço indeterminado e perigoso, pondo-se à prova e buscando nele sua oportunidade, sua ocasião. (p.160)

4 Em 1990, o Sistema Nacional de Avaliação da Educação Básica (SAEB) realiza a sua primeira avaliação. A partir de 1995, as avaliações focam os anos de conclusão das etapas da educação básica. Em 1998 o MEC propõe em caráter facultativo, o Exame Nacional de Ensino Médio (ENEM). Em 2002 foi criado o Exame Nacional de Certificação de Competência de Jovens e Adultos (ENCCEJA). (MEC/INEP, 2010).

5 A Prova Brasil, por exemplo, se apresenta como uma avaliação censitária do ensino urbano. Ela fornece as médias de desempenho para o Brasil, regiões e unidades da federação para cada um dos municípios e escolas que participam. A iniciativa dessa proposta pela União no contexto do "Plano de Metas" tem por objetivo possibilitar a realização de um diagnóstico do nível de alfabetização das crianças da rede pública de ensino no segundo ano de escolaridade. (Decreto n. 6.094/2007)

6

Disponível in: http://portal.mec.gov.br/cne/arquivos/pdf/CEB017 2001.pdf

7 http://portal.mec.gov.br/cne/arquivos/pdf/CEB02 01.pdf

8 FOUCAULT (2010).

\section{Referências}

ACORSI, R. Tenho 25 alunos e 5 inclusões. In LOPES M. C \& HATTGE M.D. (org) Inclusão Escolar: Conjunto de práticas que governam. Belo Horizonte: Autentica, PP. 169-184. 2009.

CASTRO-GÓMEZ, S. Historia de la gubernamentalidad. Razón de Estado, liberalismo y neoliberalismo en Michel Foucault. $1^{a}$ ed. Bogotá: Siglo del Hombre Editores, 2010.
$280 \mathrm{p}$.

COLLARES, C. L., \& MOYSÉS, M. A. A.. A transformação do espaço pedagógico em espaço clínico (A Patologização da Educação). Série Ideias (23), São Paulo, FDE, 1994. P.25-31.

DECLARAÇÃO UNIVERSAL DOS DIREITOS <HTTP://www.mj.gov.br/sedh/ct/legis_intern/ddh_ bid_inter_universal.htm>. Acesso em 15.jun.2014.

DELCARAÇÃO DE SALAMANCA. Disponível em:

$<$ http://portal.mec.gov.br/seesp/arquivos/pdf/salama nca.pdf $>$ Acesso em 15.jun.2014.

DELEUZE, G. A filosofia. In DELEUZE, G. Nietzche. LISBOA: Ed. 70, pp17-34. 1994

FOUCAULT, M. Nascimento da biopolítica. $1^{\mathrm{a}} \mathrm{ed}$. São Paulo: Martins Fontes, 2008.

FOUCAULT, M. Os Anormais. São Paulo: Martins Fontes, 2001.

FOUCAULT, M. Vigiar e punir: história da violência nas prisões. $38^{\mathrm{a}}$ Ed. Petrópolis, RJ: Vozes. 2010.

GALLO, S. Uma apresentação: diferenças e educação; governamento e resistência. In LOPES M. C \& HATTGE M.D. (org) Inclusão Escolar: Conjunto de práticas que governam. Belo Horizonte: Autentica, pp.7-12. 2009

GALLO, S. Em torno de uma educação menor: variáveis e variações. $36^{\text {a }}$ Reunião Nacional da ANPEd -2013, Goiânia-GO (2013). Diponivel in: http://36reuniao.anped.org.br/pdfs_trabalhos_encom endados/gt13_trabencomendado_silviogallo.pdf

GOFFMAN, E. Manicômios, prisões e conventos. São Paulo: Perspectiva. 2003. $7^{\text {a }}$ Ed.

KLEIN, R.R. Reprovação escolar: prática que governa. In LOPES M. C \& HATTGE M.D. (org) Inclusão Escolar: Conjunto de práticas que governam. Belo Horizonte: Autentica, pp.13-32. 2009.

ROOS, A.P. Sobre a (in)governabilidade da diferença. In LOPES M. C \& HATTGE M.D. (org) 
Inclusão Escolar: Conjunto de práticas que governam. Belo Horizonte: Autentica, pp.13-31. 2009.

VEIGA-NETO A. Incluir para excluir in Jorge Larrosa e Carlos Skliar (org.). Habitantes de Babel: políticas e poéticas da diferença. Belo Horizonte, Autêntica, 2001, pp.105-118.

VEIGA-NETO A. \& LOPES M. C. Inclusão, exclusão, in/exclusão. Verve, 20. 2011, pp.121135 .

VEIGA-NETO, A. Educação e governamentalidade neoliberal. Texto apresentado e discutido no Colóquio Foucault, realizado na Universidade do Estado do Rio de Janeiro (UERJ), em novembro de 1999, sob a coordenação da Dra Vera Portocarrero. 1999.

Disponível

em: http://www.lite.fe.unicamp.br/cursos/nt/ta5.13.htm

\section{Sobre a autora:}

Alexandrina Monteiro: é professora da Universidade São Francisco, atualmente faz pós-doutorado em filosofia da Educação na Unicamp sob supervisão do Prof. Silvio Gallo. É Integrante do Grupo de Pesquisa em Educação, Linguagem e Práticas Culturais. (PHALA/UNICAMP/CNPq). Atua na área de Educação, com ênfase em Estudos Curriculares, Linguagem e Práticas Sociais. Atua principalmente nos seguintes temas: Currículo como campo discursivo, Linguagem e Subjetivações, Educação de Jovens e Adultos.

Recebido em 20/10/2014

Aprovado em 19/12/2014 